\title{
Preautopsy imaging in cerebro-costo-mandibular syndrome
}

\author{
Alan E. Oestreich • Jerzy W. Stanek
}

Received: 26 February 2010 /Revised: 19 March 2010 / Accepted: 20 April 2010 /Published online: 13 May 2010

(C) Springer-Verlag 2010

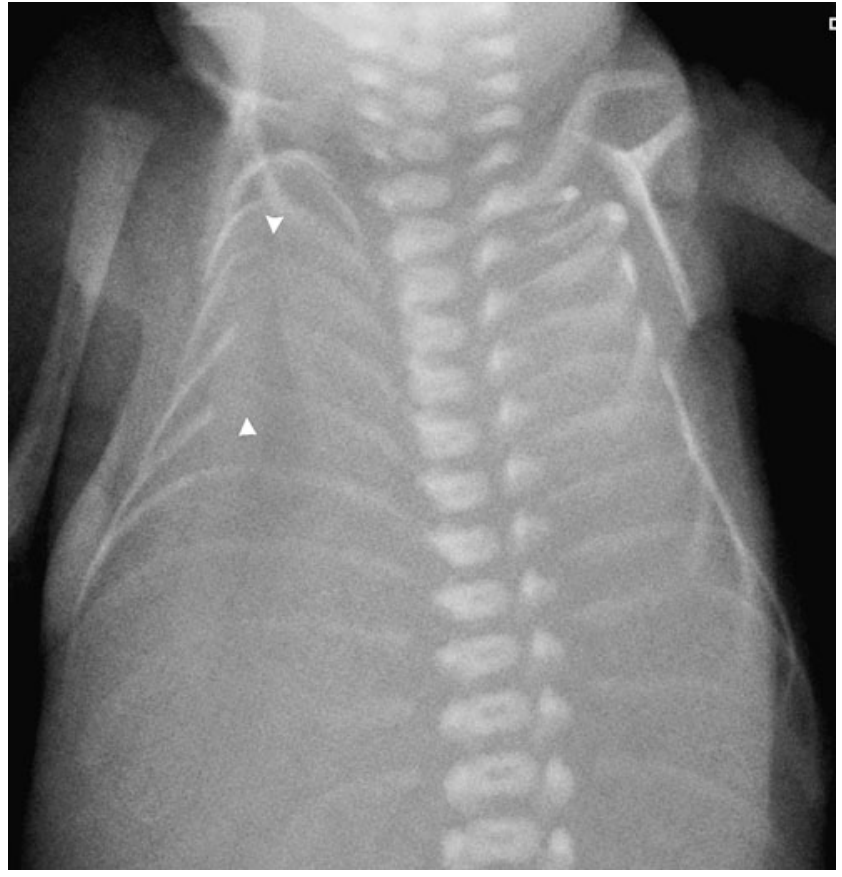

The 23-week pregnancy of a gravida 2 para 1 mother was terminated after a prenatal US revealed fetal hydrops and congenital anomalies. Because of external anomalies, preautopsy radiographs were performed (Fig. 1). Pathognomic right rib gaps (arrowheads) (Fig. 1) allowed a diagnosis of cerebro-costo-mandibular syndrome [1], which was immediately discussed with the pathologist, including the likelihood of intracranial abnormality. The autopsy confirmed fibrovascular replacement of portions of the right posterior ribs (Fig. 2), as well as extensive, predominantly perivascular, brain calcifications.

The preautopsy identification of rib gaps allowed the diagnosis of cerebro-costal-mandibular syndrome, a hereditary condition. This identification helped facilitate the autopsy. Because they are seldom seen, rib gaps could have easily passed unnoticed on a routine autopsy. Bone fails to form, but the pathogenesis is unknown. Moreover, the need for intracranial imaging or an autopsy examination becomes evident [2]. We emphasize the value of preautopsy radiological imaging with immediate interpretation.

Fig. 1 Preautopsy frontal radiograph

Fig. 2 Photomicrograph of one rib gap, H\&E. *=bone; $\S=$ intervening fibrous tissue; arrow $=$ periosteum

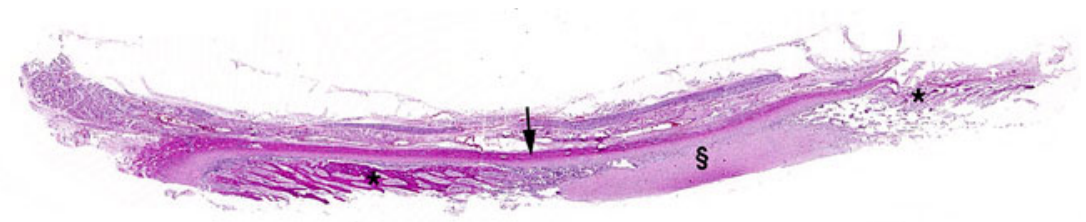

A. E. Oestreich $(\bowtie)$

Department of Radiology 5031,

Cincinnati Children's Hospital Medical Center,

3333 Burnet Ave.,

Cincinnati, OH 45229-3039, USA

References

e-mail: alan.oestreich@cchmc.org

\section{J. W. Stanek}

Department of Pathology,

Cincinnati Children's Hospital Medical Center,

3333 Burnet Ave.,

Cincinnati, OH 45229-3039, USA

1. Silverman FN, Strefling AM, Stevenson DK et al (1980) Cerebrocosto-mandibular syndrome. J Pediatr 97:406-416

2. Winter RM, Baraitser M (2006) Cerebro-costo-mandibular syndrome. London Medical Databases. Oxford University Press, London. Available via www.lmdatabases.com. Accessed 22 Feb 2010 